\title{
ОЦЕНКА РАСПРОСТРАНЕННОСТИ ЗЛОКАЧЕСТВЕННЫХ НОВООБРАЗОВАНИЙ В РОССИИ С ПРИМЕНЕНИЕМ МОДЕЛИ ЗАБОЛЕВАЕМОСТЬ-СМЕРТНОСТЬ
}

\author{
РусТАМ ТУРСУН-ЗАДЕ
}

\begin{abstract}
В данной работе предпринимается попытка оиенки непубликуемых производных показателей онкологической заболеваемости и смертности в населении РФ с использованием таблии множественного выбытия - популяциионной модели рака Д. Дюшен в сложившихся условиях ограниченной доступности медико-демографических данных. Смоделированные таким образом показатели (средний возраст заболевания злокачественными новообразованиями (ЗНО), средняя ожидаемая продолжительность болезни, распространенность ЗНО в населении и средний возраст смерти от 3НО) позволят определить, происходит ли в России рост распространенности ЗНО и является ли этот рост результатом экспансии заболеваемости ЗНО (понимаемой как среднее увеличение времени, прожитого в состоянии нездоровья, обусловленного этим заболеванием)?
\end{abstract}

Показано, что в России наблюдается сонаправленный рост среднего возраста заболевания $3 Н О$ среднего возраста смерти от 3 НО с приматом последнего. Результатом этих изменений является увеличение среднего числа лет, прожитых с ЗНО, а также рост распространенности 3 НО в населении РФ. Отмечень локализации с наибольшим и наименьшим наблюдаемым ростом распространенности ЗНО, а также локализации исключения из выраженной тенденции к этому pocmy.

На основании проведенного анализа можно утверждать, что в России происходит экспансия заболеваемости ЗНО, выраженная в увеличении среднего числа лет, прожитого в состоянии неполного здоровья. Исключением является локализация «ЗНО губы, полости рта, глотки и пищевода» (С00-С15) у женщчи, для которой отмечается компрессия заболеваемости, выраженная в сокращении числа лет, прожитых с ЗНО.

Ключевые слова: таблицы множественного выбытия, смертность и заболеваемость злокачественными новообразованиями, распространенность злокачественных новообразований, производные онкологической смертности и заболеваемости, анализ данных онкологической статистики.

\section{ВВЕДЕНИЕ}

В настоящее время злокачественные новообразования (ЗНО) являются второй по значимости причиной смерти населения в мире. По оценкам ВО3, в 2015 г. количество смертей, вызванных ЗНО, равнялось 8,8 млн [WHO 2017], уступая лидирующее место только количеству смертей, вызванных сердечно-сосудистыми заболеваниями. Существует мнение, что новообразования, во многих странах с высоким доходом уже являющиеся первой по значимости причиной смерти населения, в ближайшие десятилетия станут основной причиной не только смерти, но и инвалидизации населения в мире [Bray et al. 2012].

РУСТАм ТИМУРОВИч ТУРСУН-ЗАДЕ (rtursun-zade@hse.ru), НАЦИОНАЛЬНЫЙ ИССЛЕДОВАТЕЛЬСКИЙ УНИВЕРСИТЕТ «ВЫСШАЯ ШКОЛА ЭКОНОМИКИ», РОССИЯ.

ИССЛЕДОВАНИЕ ФИНАНСИРОВАЛОСЬ В РАМКАХ ПРОГРАММЫ ГОСУДАРСТВЕННОЙ ПОДДЕРЖКИ ВЕДУЩИХ УНИВЕРСИТЕТОВ РОССИЙСКОЙ ФЕДЕРАЦИИ « 5-100».

СТАТЬЯ ПОСТУПИЛА В РЕДАКЦИЮ В ИЮЛЕ 2018 Г. 
Традиционно в России смертность населения определяла в основном так называемая «большая четверка» причин: болезни системы кровообращения (БСК), новообразования, внешние причины смерти и болезни органов дыхания [Вишневский 2014]. В последние годы (начиная с 2006 г.), болезни органов пищеварения сместили на 5-ю позицию болезни органов дыхания, заняв соответственно 4-ю позицию в структуре смертности по причинам [Росстат 2017; Щербакова 2018]. С 2003 г. в России формируются условия, определяющие рост ожидаемой продолжительности жизни (ОПЖ) населения [Shkolnikov et al. 2013]. Эти условия во многом определяются снижением избыточной смертности, вызванной БСК и внешними причинами смерти [Андреев, Кваша, Харькова 2014].

В возрастном разрезе этот рост обеспечивался в основном за счет двух возрастных групп: детской до 15 лет и пожилой 65+ лет [Андреев, Кваша, Харькова 2014]. Наблюдаемое снижение коэффициентов смертности от цереброваскулярных заболеваний привело к тому, что в настоящий момент она снизились до исторического минимума у женщин и приближаются к таковому у мужчин [Grigoriev et al. 2014]. Данные тенденции явились в достаточной степени стабильными и долгосрочными, чтобы заговорить о начале первой стадии сердечно-сосудистой революции в РФ.

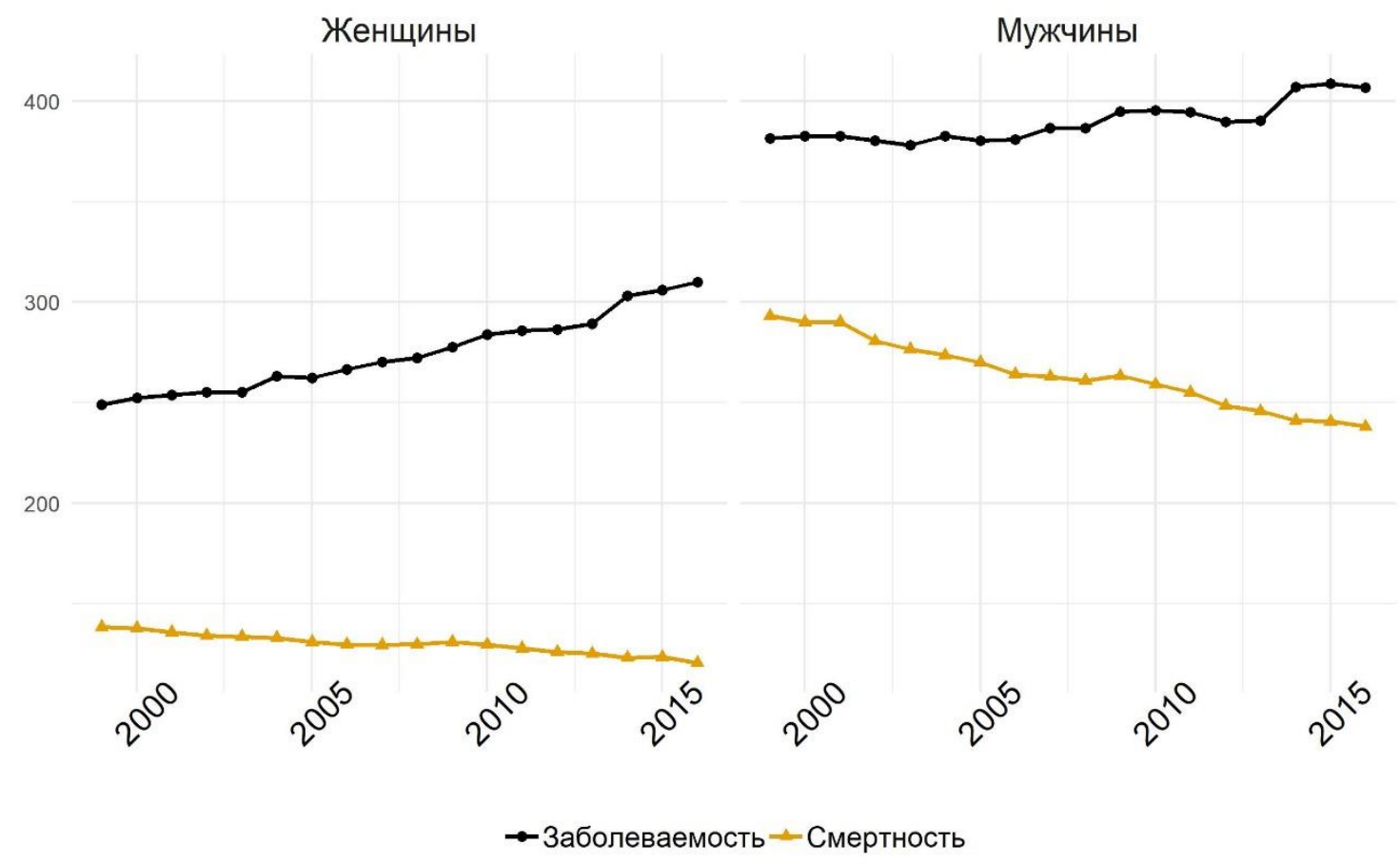

Рисунок 1. Стандартизованные по возрасту коэффициенты смертности и заболеваемости злокачественными новообразованиями, все локализации, на 100000 населения, 1999-2016

Источник: Расчет автора на основе данных, описанных в разделе "Данные и методы».

Стандартизачия выполнена прямым методом с использованием европейского возрастного стандарта.

Злокачественные новообразования являются второй по значимости причиной смерти населения в РФ. В 2016 г. 15,6\% всех зарегистрированных в РФ смертей были вызваны ЗНО [Каприн, Старинский, Петрова 2018а]. На рисунке 1 представлена динамика 
стандартизованных по возрасту коэффициентов смертности и заболеваемости населения РФ всеми ЗНО за период с 1999 по 2016 г.

На рисунке 1 очевидна тенденция к снижению стандартизованных по возрасту коэффициентов смертности, однако стандартизованные коэффициенты заболеваемости в рассматриваемый период неуклонно росли, причем в 2014 г. наблюдалось увеличение скорости их роста.

Так как известно, что заболеваемость ЗНО увеличивается с возрастом и в основном сосредоточена в пожилых возрастах (наибольшее число заболеваний в 2016 г. приходилось на возрастную группу 65-69 лет) [Каприн, Старинский, Петрова 2018а], то при учете происходящего в России процесса старения населения нет оснований ожидать сокращения числа случаев заболевания ЗНО. Логичным следствием в сложившейся ситуации может стать рост распространенности ЗНО в населении РФ, а следовательно, и рост их значимости как фактора инвалидизации населения.

К сожалению, несмотря на наличие развитого института сбора и обработки статистической информации об онкологической заболеваемости (данные собираются с 1953 г., а в 1996 г. принят законопроект о создании Федерального ракового регистра ${ }^{1}$ ), принятая в современной России практика не предусматривает полноценной публикации данных по распространенности ЗНО в населении. В ежегодниках «Состояние онкологической помощи населению», выпускаемых куратором Федерального популяционного ракового регистра Институтом им. П.А. Герцена Минздрава России с 2007 г., содержатся только общие коэффициенты распространенности в расчёте на 100 тыс. населения без половозрастного распределения [Каприн, Старинский, Петрова 2018b]. Данные по распространённости ЗНО в населении можно было бы получить из популяционных раковых регистров, однако существуют сомнения, касающиеся возможностей современной отечественной онкологической службы осуществлять пожизненный мониторинг больных $3 \mathrm{HO}$, своевременно снимать больных с учета в случае их смерти, а также полноценно регистрировать все случаи ЗНО, выявленные посмертно, равно как и полноценно связывать данные заболеваемости с данными по смертности. В частности, насколько нам известно, после ратификации в 2006 г. закона о персональных данных ${ }^{2}$ Федеральный раковый регистр потерял возможность проводить персонифицированную проверку данных, оперируя в настоящий момент массивом деперсонифицированных агрегированных данных ${ }^{3}$. Таким образом, в значительной степени было затруднено получение регистрами достоверных данных о смертях онкологических больных, ранее внесенных в регистр [Петрова, Старинский, Грецова 2016], следствием чего может стать недостоверность данных о накоплении контингентов (распространенности) вследствие несвоевременного снятия пациентов с учета. Эта проблема стояла особенно остро в первые годы после ратификации закона о персональных данных, однако в

\footnotetext{
${ }^{1}$ Приказ Министерства здравоохранения Российской Федерации от 23 декабря 1996 г. №420 «О создании Государственного ракового регистра».

2 Федеральный закон от 27 июля 2006 г. №152-Ф3 «О персональных данных».

${ }^{3}$ Приказ Министерства здравоохранения Российской Федерации от 19 апреля 1999 г. №135 «О совершенствовании системы Государственного ракового регистра».
} 
настоящее время ситуация несколько улучшилась. Популяционные раковые регистры находят новые способы взаимодействия, однако в настоящий момент проблема все еще далека от решения [Петрова, Старинский, Грецова 2016].

В своих ежегодных статистических отчетах «Злокачественные новообразования в России: заболеваемость и смертность» [Каприн, Старинский, Петрова 2014, 2015, 2016, 2017, 2018а; Чиссов, Старинский, Петрова 2009, 2010, 2011, 2012, 2013] Институт им. П.А. Герцена указывает, что использует данные по смертности, полученные из статистической таблицы C51 Росстата «Распределение умерших по полу, возрастным группам и причинам смерти», де-факто независимого от непосредственно регистрации заболеваемости ЗНО и структуры Минздрава источника данных. Данная таблица используется, несмотря на то, что смертность в ней учитывается по краткой номенклатуре причин смерти МКБ-10 с ограниченным набором локализаций. В тоже самое время, на уровне регионов, показатель распространённости ЗНО формируется на основании базы данных (записей о случаях заболевания и смерти пациентов) самого регистра, что может повлечь за собой недостоверную оценку показателя распространенности ввиду отсутствия возможности своевременного снятия с учета пациентов выбывших из региона, либо скончавшихся на территории не подотчетной раковому регистру. Ввиду недостаточной сопоставимости полноты регистрации данных по заболеваемости и смертности, осуществляемой в рамках двух ведомств, а также возможного недоучета смертей онкологическими регистрами на уровне регионов, можно предположить неполную достоверность данных по распространенности, содержащихся как в Федеральном, так и в территорияальных популяционных раковых регистрах.

Если в населении действительно наблюдается рост распространенности ЗНО, то важно выявить причины этого роста. Является ли он исключительно следствием роста заболеваемости, или же мы имеем дело с увеличением продолжительности болезни, выраженного в увеличении среднего числа лет, прожитых в состоянии нездоровья (феномена, получившего название экспансия заболеваемости)? [Fries 1980, 2005].

Мы предлагаем использовать демографический метод таблиц множественного выбытия (multidecrement life tables), разработанный Д. Дюшен [Duchêne 2002], для моделирования непубликуемых производных онкологической заболеваемости и смертности в населении РФ. Эти производные (средний возраст заболевания ЗНО, средняя продолжительность болезни, распространенность ЗНО в населении и средний возраст смерти от ЗНО) позволят нам определить, происходит ли в РФ рост распространенности ЗНО и является ли этот рост результатом экспансии заболеваемости.

Смоделированные для стационарного населения таблиц смертности данные, хотя и не могут считаться полноценной заменой данным реальным, тем не менее могут быть использованы для оценки динамики популяционных процессов.

\section{ДАННЫЕ И МЕТОДЫ}

Мы предлагаем использовать популяционную модель рака (в дальнейшем именуемую 
«модель Дюшен» [Duchêne 2002]) для оценки не публикуемых обычно производных показателей онкологической заболеваемости и смертности. Модель основывается на повозрастных коэффициентах смертности и заболеваемости и вычисляется методом таблиц множественного выбытия. Мы применяем модель Дюшен для моделирования распространённости ЗНО, а также ряда производных показателей: среднего возраста заболевания ЗНО, среднего возраста смерти от ЗНО, средней продолжительности болезни. Данный метод получил дальнейшую реализацию и был подробно описан в техническом отчете Института им. Макса Планка [Andreev, Shkolnikov, Jasilionis 2018].

Предположив, что смертность и заболеваемость до определенного года $x$ были равны таковым в рассматриваемом году $x$, мы можем рассчитать распространённость ЗНО в стационарном населении таблицы смертности для года $x$. Для этого в первую очередь необходимо рассчитать долю гипотетического населения таблицы смертности, страдающего ЗНО, в определенном возрастном интервале, равном по длине $x$ годам, по следующей формуле:

$$
P i_{x}=\frac{L_{x}^{c}}{L x}
$$

где $L_{x}^{c}$ - число лет, прожитых больными ЗНО, в возрастном интервале, равном $x$ годам;

- $L_{X}$ число лет, прожитых всем населением таблицы смертности в возрастном интервале, равном $х$ годам.

Произведением полученных коэффициентов $P i_{x}$ и реальной повозрастной численности среднегодового населения РФ, проживающего в определённом возрастном интервале, равном $x$ годам, мы оцениваем распространенность ЗНО в населении, проживающем в возрастном интервале, равном $x$ годам:

$$
C_{p r}=P i_{x} * P_{x}
$$

где $P i_{x}$ - доля населения, больного ЗНО, проживающего в возрастном интервале, равном $x$ годам;

$P_{x}$ - численность населения, проживающего в возрастном интервале, равном $x$ годам.

При расчетах модели использовались повозрастные (по 5-летним возрастным интервалам) коэффициенты смертности от всех причин смерти $M_{x}$, аналогичные им коэффициенты смертности по причинам смерти $M_{x}^{c}$ и повозрастные коэффициенты заболеваемости $3 \mathrm{HO}$ для рассматриваемых локализаций $I_{x}^{c}$. Модель рассчитывается для 5летних возрастных интервалов, начиная с интервала 15-19 лет и заканчивая открытым интервалом $85+$ лет.

В данной работе мы рассматриваем следующие диагностические категории:

- все злокачественные новообразования (С00-С97);

- ЗНО губы, полости рта, глотки и пищевода (С00 - С15);

- ЗНО желудка (C16);

- ЗНО кишечника и прямой кишки (колоректальный рак) (C17 - С21); 
- 3 ЗНО трахеи, бронхов и легкого (С33 - С34);

- 3 З жО женской молочной железы (C50);

- 3 ЗНО женских половых органов (С51 - С58);

- ЗНО предстательной железы (С61);

- все другие злокачественные новообразования.

В скобках указаны коды согласно Международной классификации болезней 10-го пересмотра (МКБ-10).

Для расчетов коэффициентов заболеваемости мы использовали данные государственной статистической отчетности по форме №7 «Отчет о заболеваниях злокачественными новообразованиями», опубликованные в статистических ежегодниках Института им. П.А. Герцена «Злокачественные новообразования в России» [Каприн, Старинский, Петрова 2014, 2015, 2016, 2017, 2018а; Чиссов Старинский, Петрова 2009, 2010, 2011, 2012, 2013], а также в статистическом сборнике «Злокачественные новообразования в России в 1993-2013 годах» [Петрова и др. 2015]. Для расчетов коэффициентов смертности использованы данные таблиц С51 Росстата. Для расчетов повозрастных коэффициентов распространенности ЗНО мы применяли данные по среднегодовой численности населения по 5-летним возрастным интервалам. До 2014 г. данные по заболеваемости и смертности не учитывают Республику Крым и город Севастополь.

В данной работе рассматривается временной промежуток с 1999 по 2016 г. Выбор 1999 г. оправдан переходом РФ на Международную классификацию болезней 10-го пересмотра (МКБ-10), что позволяет исключить возможные неточности вследствие переклассификации причин при переходе с одной редакции МКБ в другую. Необходимо также отметить, что заболеваемость и смертность практически от всех рассматриваемых локализаций наблюдается, начиная с возрастного интервала 15-19 лет, что оправдывает выбор данного интервала в качестве стартового для расчетов модели. События в возрастных интервалах ниже указанного не учитываются при расчетах популяционной модели рака.

\section{РезУльтаты}

На рисунке 2 представлена динамика среднего возраста заболевания ЗНО в России. Следует отметить, что для диагностической группы «другие ЗНО» для мужского населения модель Дюшен не позволяет рассчитать рассматриваемые нами показатели среднего возраста заболевания и смерти от ЗНО, а также среднюю продолжительность болезни до 2007 г. на основе имеющихся входных данных.

На рисунке 2 мы видим, что для диагностической категории «все ЗНО» средний возраст заболевания у мужчин превосходит таковой у женщин. В последние годы (после 2004 г.) наблюдается выраженная тенденция к дивергенции, являющейся результатом продолжающегося роста среднего возраста заболевания ЗНО у мужчин и одновременного выхода на плато у женщин. Для данной диагностической категории средний возраст заболевания у мужчин до 2004 г. был примерно равен таковому у женщин, однако с 2005 
по 2007 г. у мужчин наблюдается резкий рост среднего возраста заболевания ЗНО, замедляющийся в 2007 и 2008 г. и увеличивающийся впоследствии вплоть до 2016 г. После 2004 г. средний возраст заболевания ЗНО у женщин, хотя и продолжает расти, уступает таковому у мужчин, причем данный разрыв увеличивается, начиная с 2008 г. В последние годы наблюдения сколько-нибудь значимого роста среднего возраста заболевания ЗНО у женщин не фиксируется. Учитывая, что для всех других рассматриваемых нами диагностических категорий в отдельности средний возраст заболевания ЗНО у женщин превосходит таковой у мужчин, можно сделать вывод, что данная разница может определяться локализациями, не свойственными мужскому полу.

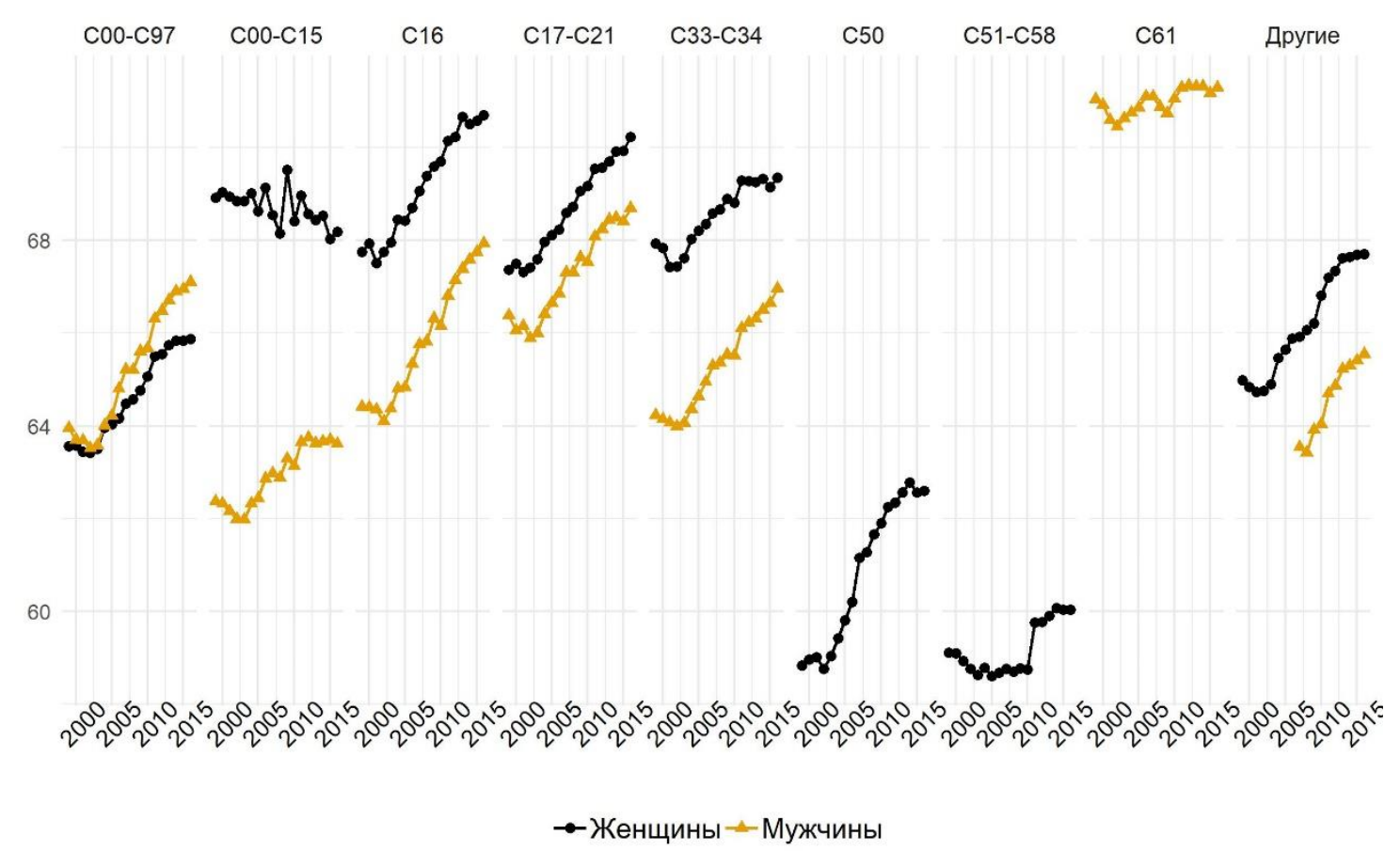

Рисунок 2. Средний возраст заболевания ЗНО, 1999-2016

С00-С97- все локализаџии; С00 - С15 - ЗНО губы, полости рта, глотки и пищевода; С33 - С34 - ЗНО трахеи, бронхов и легкого; С16 - ЗНО желудка; С17 - С21 - ЗНО кишечника и прямой кишки (колоректальный рак); С50 - 3НО женской молочной железы; С51 - С58 - ЗНО женских половых органов; С61 - ЗНО предстательной железы.

Источник: Расчет автора на основе данных, описанных в разделе «Данные и методы».

Проанализируем особенности динамики среднего возраста заболевания для рассматриваемых нами диагностических категорий.

Для ЗНО желудка начало роста среднего возраста заболевания приходится на 2003 г. у мужчин и на 2002 г. у женщин, фиксируется заметный прирост показателя с незначительным снижением его у женщин в 2014 г.

Начало роста для диагностической категории «колоректальный рак» приходится на 2003 г. у мужчин и на 2001 г. у женщин, у женщин устойчивый рост наступает после небольшого снижения между 2000 и 2001 г., у мужчин рост наблюдается с 2002 г. 
Для ЗНО трахеи, бронхов и легкого у мужчин рост наблюдается с 2003 г., у женщин - с 2001 г., в то время как для ЗНО молочной железы значительный рост наблюдается с 2002 г., а для других 3НО - с 2002 г. у женщин и с 2008 г. у мужчин.

Стоит отдельно рассмотреть показатели ЗНО женских половых органов и ЗНО предстательной железы, так как особенности их динамики отличаются от таковых, наблюдаемых для других локализаций. Показатель среднего возраста заболевания пациентов с ЗНО женских половых органов снижался вплоть до 2003 г., затем после некоторого роста в 2004 г. и последовавшего за этим снижения в 2005 г. показатель выходит на плато, колеблясь в значениях 58,7 года вплоть до 2011 г., когда происходит значительный рост с последующим выходом на очередное плато вплоть до конца рассматриваемого периода. Средний возраст заболевания ЗНО предстательной железы за рассматриваемый период растет незначительно, колеблясь в значениях, равных 71 году.

Для ЗНО губы, полости рта, глотки и пищевода у мужчин после периода снижения, приходящегося на 1999-2003 гг., наблюдается последовательный рост вплоть до 2016 г. У женщин динамика среднего возраста заболевания ЗНО данной диагностической категории является исключением из общей тенденции к росту. Вплоть до 2006 г. показатель колеблется в районе 69 лет, затем в 2007-2008 гг. происходит его резкое снижение с последующим значительным увеличением в 2009 г. до отметки 69,5 года и дальнейшим снижением до значения, равного 68,2 года в 2016 г., что ниже уровня, зарегистрированного в 1999 г. (68,9 года).

Наиболее значительное увеличение среднего возраста заболевания у мужчин наблюдается для ЗНО желудка, трахеи, бронхов и легкого, колоректального рака, других ЗНО, ЗНО губы, полости рта, глотки и пищевода. Наименьший рост наблюдается для ЗНО предстательной железы, однако тут следует отметить, что данная диагностическая категория изначально являлась категорией с самым высоким регистрируемым возрастом заболевания, в то время как локализацией с наименьшим регистрируемым возрастом заболевания $3 \mathrm{HO} \mathrm{у} \mathrm{мужчин} \mathrm{является} 3 \mathrm{HO}$ губы, полости рта и пищевода. Наиболее значительное увеличение среднего возраста заболевания у женщин наблюдается для ЗНО молочной железы, желудка, колоректального рака, других 3НО, ЗНО трахеи, бронхов и легкого и женских половых органов. Для ЗНО губы, полости рта, глотки и пищевода у женщин наблюдается снижение среднего возраста заболевания. Локализацией с наименьшим регистрируемым возрастом заболевания является ЗНО женской молочной железы, в то время как локализацией с наибольшим возрастом - ЗНО желудка.

Рост среднего возраста заболевания у мужчин был в целом более значительным, чем у женщин, практически для всех рассматриваемых диагностических категорий, за исключением колоректального рака и других ЗНО. Этот рост во многом определяется такими локализациями, как ЗНО желудка, а также трахеи, бронхов и легкого. У женщин лидирующую позицию занимают ЗНО молочной железы, желудка и колоректальный рак. Наибольшая разница в среднем возрасте заболевания у мужчин и женщин регистрируется для ЗНО губы, полости рта, глотки и пищевода, ЗНО желудка и ЗНО трахеи, бронхов и легкого, в то время как наименьшая - для колоректального рака. 
Обратимся к динамике среднего возраста смерти от ЗНО (рисунок 3).

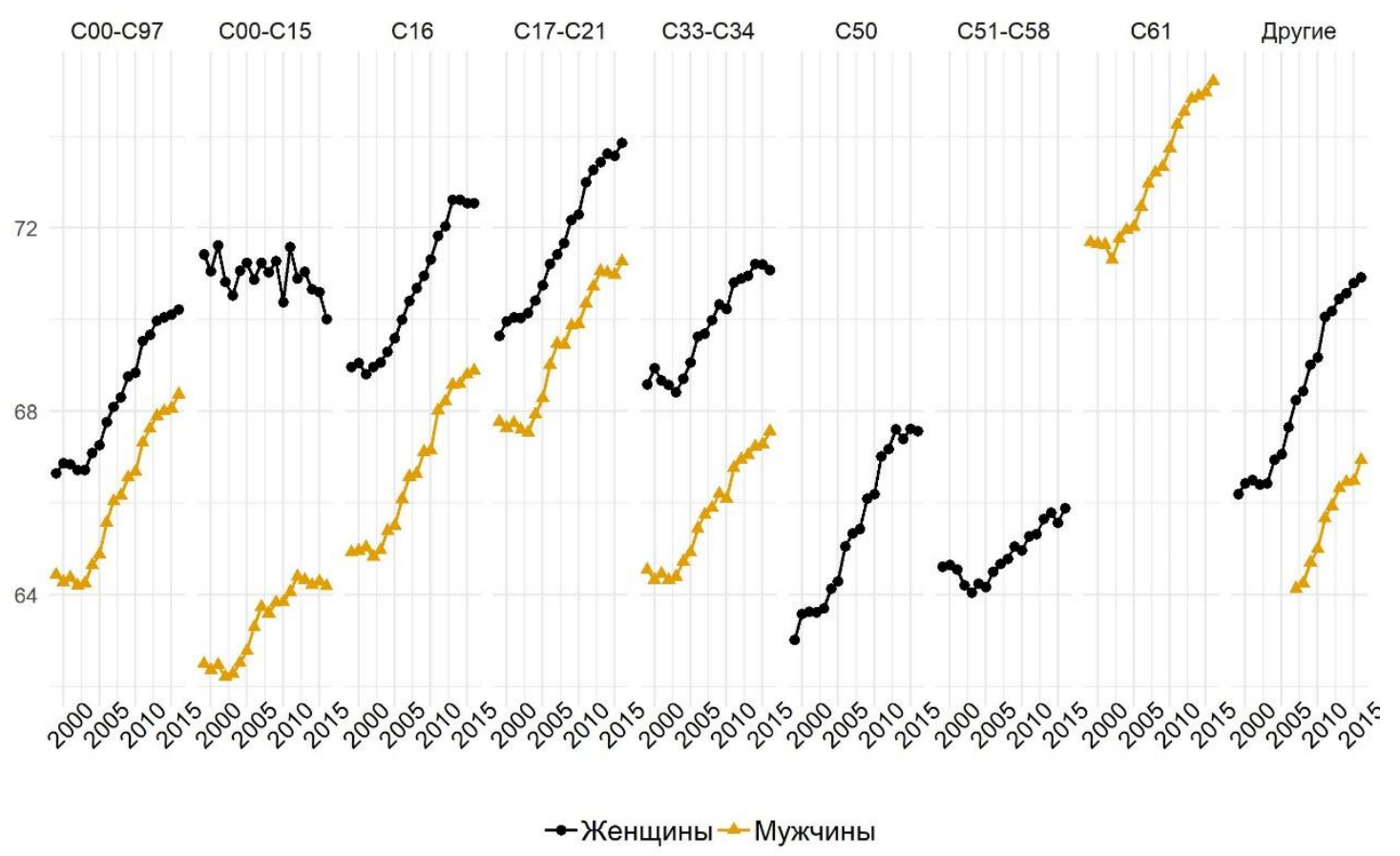

Рисунок 3. Средний возраст смерти от ЗНО, 1999-2016

С00-С97- все локализаџии; С00 - С15 - ЗНО губы, полости рта, глотки и пищевода; С33 - С34 - ЗНО трахеи, бронхов и легкого; С16 - ЗНО желудка; С17 - С21 - ЗНО кишечника и прямой кишки (колоректальный рак); С50 - ЗНО женской молочной железы; C51 - С58-3НО женских половых органов; С61 - ЗНО предстательной железы.

Источник: Расчет автора на основе данных, описанных в разделе «Данные и методы».

На рисунке 3 видно, что средний ожидаемый возраст смерти, вызванной ЗНО, у женщин превосходит таковой у мужчин для всех рассматриваемых диагностических категорий. Наблюдается устойчивая тенденция к увеличению показателя, исключением служат только ЗНО губы, полости рта, глотки и пищевода у женщин. К локализациями с наибольшим регистрируемым возрастом смерти относятся 3НО предстательной железы у мужчин и колоректальный рак у женщин; с наименьшим регистрируемым возрастом смерти - ЗНО губы, полости рта, глотки и пищевода у мужчин и половых органов у женщин.

Рост среднего возраста смерти для всех умирающих от рака наблюдается с 2002 г. у мужчин и с 2003 г. у женщин, но для разных локализаций динамика была различной. Для ЗНО желудка этот рост идет с 2002 г. у мужчин и с 2001 г. у женщин; для «колоректального рака - с 2003 г. у мужчин и с 1999 г. у женщин; для ЗНО трахеи, бронхов и легкого с 2003 г. у мужчин и с 2004 г. у женщин; для других ЗНО рост показателя регистрируется с первых лет наблюдений как для мужчин, так и для женщин; для ЗНО молочной железы рост регистрируется с 1999 г., а для ЗНО женских половых органов - после периода снижения в 2000-2003 гг. Средний возраст смерти от ЗНО предстательной железы растет с 2002 г. Средний возраст смерти от $3 \mathrm{HO}$ губы, полости рта, глотки и пищевода у мужчин растет после периода снижения, продолжавшегося до 2002 г., вплоть до 2012 г. с последующим выходом на плато. У женщин динамика этого показателя является исключением из общей 
тенденции к увеличению среднего возраста смерти от ЗНО, он колебался в районе 71 года с двумя периодами резкого снижения между 2001 и 2003 г. и в 2010 г. с наблюдаемым в 2011 г. ростом и последующим снижением вплоть до 2016 г. В 2016 г. показатель достигает значения 70,1 года, что ниже значения, наблюдаемого в 1999 г. (71,4 года). Наибольшая разница среднего возраста смерти у мужчин и у женщин наблюдается для ЗНО губы, полости рта, глотки и пищевода и ЗНО трахеи, бронхов и легкого, наименьшая - для колоректального рака. Локализации с наибольшим наблюдаемым средним возрастом смерти у мужчин - ЗНО предстательной железы, а у женщин - колоректальный рак, с наименьшим - ЗНО губы, полости рта, глотки и пищевода у мужчин и ЗНО половых органов у женщин.

За рассматриваемый период рост среднего возраста смерти превосходил рост среднего возраста заболевания ЗНО. Однако если средний возраст заболевания у мужчин для всех ЗНО был выше, чем у женщин, то с возрастом смерти наблюдается обратная ситуация. Несмотря на то, что средний возраст смерти у мужчин увеличился больше, чем у женщин, последние тем не менее умирают от всех $3 \mathrm{HO}$ на 1,9 года позже, чем мужчины. У мужчин повышение среднего возраста смерти во многом определяется ЗНО желудка, колоректальным раком и ЗНО трахеи, бронхов и легкого, в то время как у женщин другими ЗНО, ЗНО молочной железы, колоректальным раком и ЗНО желудка. Как и в случае с возрастом заболевания, максимальный возраст смерти практически для всех локализаций приходится на 2014-2016 гг. Однако значимым исключением здесь (как и в случае с заболеваемостью) являются ЗНО губы, полости рта, глотки и пищевода у женщин, для которых наблюдается тенденция к снижению среднего возраста смерти.

Перейдем к анализу динамики продолжительности болезни, в данной модели представляющей собой разность среднего возраста заболевания и среднего возраста смерти от ЗНО. На рисунке 4 представлена динамика средней ожидаемой продолжительности болезни ЗНО рассматриваемых локализаций в населении РФ.

Логичным следствием роста среднего возраста смерти, опережающего рост среднего возраста заболевания ЗНО, является увеличение значений средней продолжительности болезни, иными словами, увеличение числа лет, прожитых в состоянии неполного здоровья. Из графиков на рисунке 4 следует, что продолжительность болезни растет для всех рассматриваемых локализаций, за исключением ЗНО губы, полости рта, глотки и пищевода у женщин. Очевидно, что продолжительность болезни у мужчин значительно короче таковой у женщин, причем для категории «все ЗНО» наблюдается тенденция к дальнейшей конвергенции в значениях данного показателя. У мужчин, тем не менее, наблюдается значительный рост среднего числа лет, прожитых с ЗНО предстательной железы. За рассматриваемый период наименьшая средняя продолжительность болезни у мужчин приходится на ЗНО губы, полости рта, глотки и пищевода, а также ЗНО трахеи, бронхов и легкого со средними значениями, равными примерно 0,5 года, в то время как у женщин на 3 НО трахеи, бронхов и легкого (1,3 года) и желудка (1,5 года). Локализациями с наименее стабильной динамикой являются ЗНО молочной железы и половых органов у женщин, причем для $3 \mathrm{HO}$ женских половых органов рассматриваемый показатель принимает наибольшие значения в 2009-2010 гг. У мужчин для всех рассматриваемых 
диагностических категорий наблюдается тенденция к росту числа лет, прожитых с ЗНО. Наиболее значительный рост этого показателя у мужчин приходится на ЗНО предстательной железы, в то время как у женщин при исключении группы «другие ЗНО»на колоректальный рак. Следует, однако, отметить тенденцию к некоторому снижению средней продолжительности болезни, наметившуюся в последние годы наблюдений, наиболее ярко выраженную у женщин для следующих локализаций: ЗНО желудка, колоректальный рак и ЗНО трахеи, бронхов и легкого.

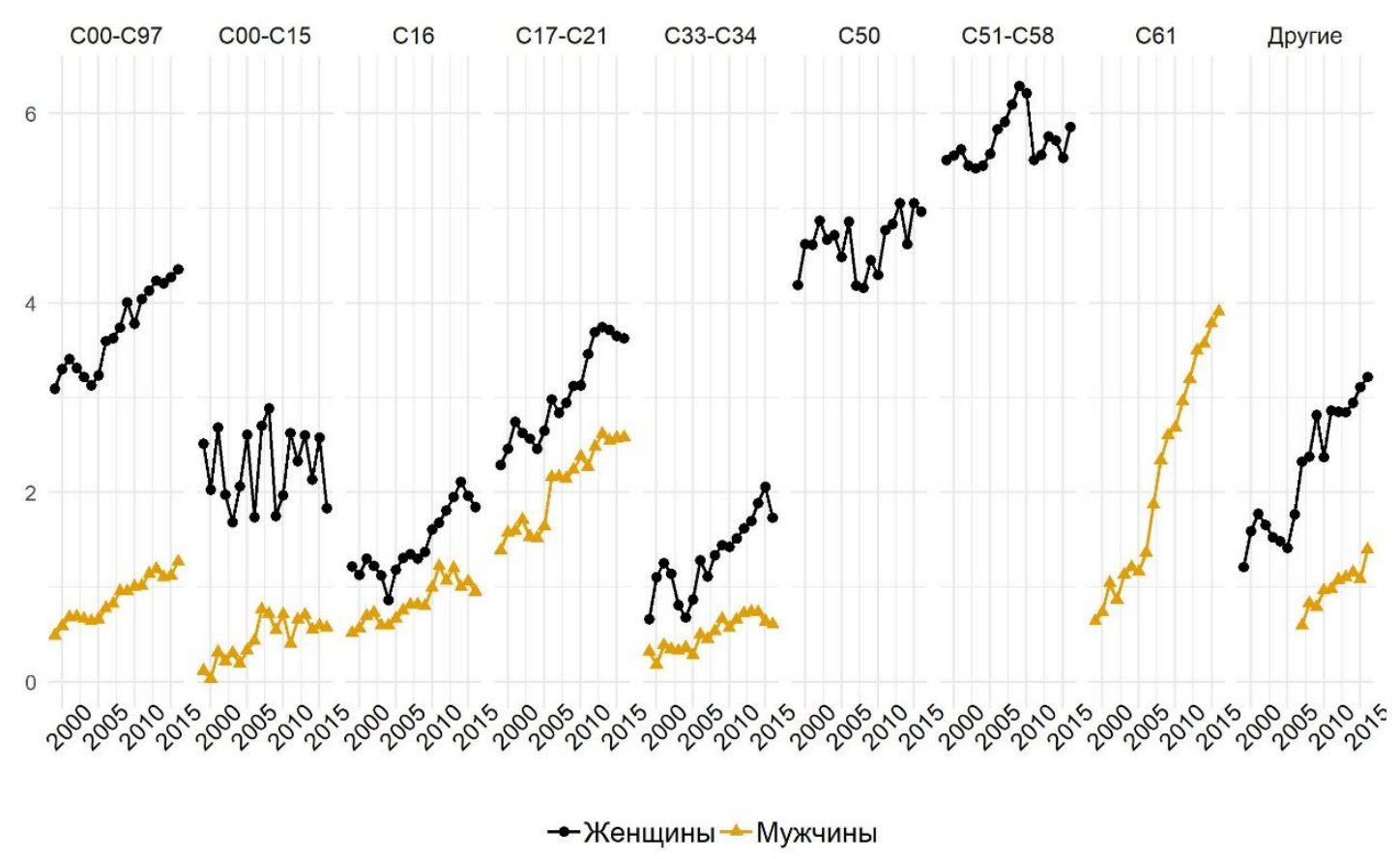

Рисунок 4. Ожидаемая продолжительности болезни, 1999-2016, лет

С00-С97- все локализации; С00 - С15 - ЗНО губы, полости рта, глотки и пищевода; С33 - С34-3НО трахеи, бронхов и легкого; С16 - ЗНО желудка; С17 - С21 - ЗНО кишечника и прямой кишки (колоректальный рак); С50 - ЗНО женской молочной железы; С51 - С58 - 3НО женских половых органов; С61 - ЗНО предстательной железы.

Источник: Расчет автора на основе данных, описанных в разделе «Данные и методы».

Рост показателя средней продолжительности болезни, выраженный в увеличении числа лет, прожитых с ЗНО, может привести к росту распространённости ЗНО в населении РФ. На рисунке 5 представлены стандартизованные по возрасту коэффициенты распространённости ЗНО рассматриваемых локализаций в населении РФ.

У мужчин, исключая группу «другие ЗНО», распространенность которых в населении является самой высокой, наиболее распространенной формой являются ЗНО предстательной железы, за которыми следуют колоректальный рак, ЗНО трахеи, бронхов и легкого и губы, полости рта, глотки и пищевода. ЗНО желудка являются наименее распространенной формой рака у мужчин, очевидно вследствие высокой летальности. Единственной локализацией у мужчин, для которой наблюдается незначительное снижение коэффициентов распространенности, является ЗНО губы, полости рта, глотки и пищевода. Наибольшая скорость роста коэффициента распространенности наблюдается для ЗНО 
предстательной железы и для колоректального рака, в то время как для распространённости ЗНО желудка и для ЗНО трахеи, бронхов и лёгкого наблюдается относительно стабильная динамика.
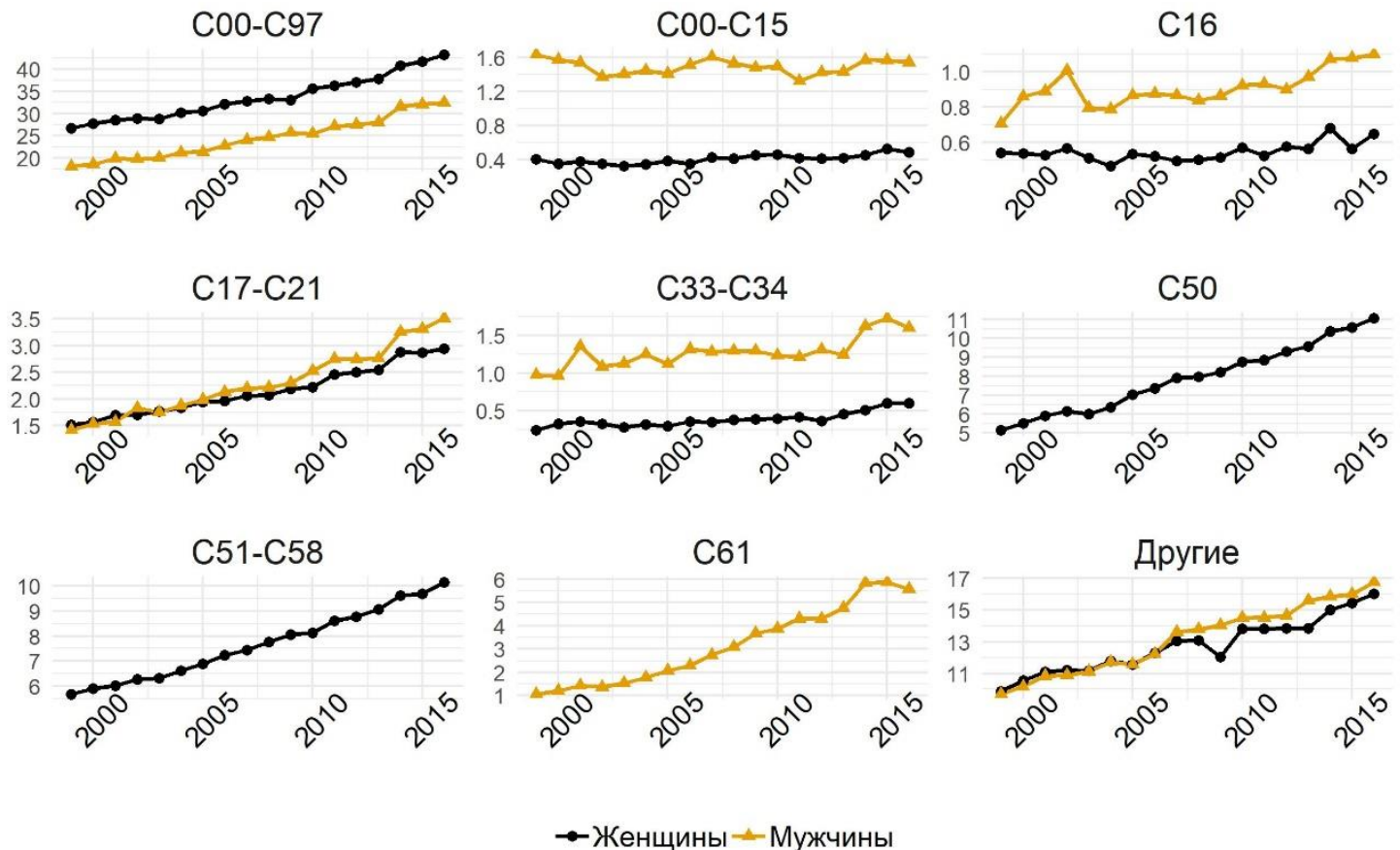

\section{Рисунок 5. Стандартизованные по возрасту коэффициенты распространенности 3 НО в населении РФ, на 1000 населения, 1999-2016}

Стандартизация выполнена прямым методом с использованием европейского возрастного стандарта.

С00-С97- все локализаџии; С00 - С15 - ЗНО губы, полости рта, глотки и пищевода; С33 - СЗ4 - ЗНО трахеи, бронхов и легкого; С16 - ЗНО желудка; С17 - С21 - ЗНО кишечника и прямой кишки (колоректальный рак); С50 - ЗНО женской молочной железы; С51 - С58 - ЗНО женских половых органов; С61 - ЗНО предстательной железы.

Источник: Расчет автора на основе данных, описанных в разделе "Данные и методы»».

Представленная на рисунке 5 динамика коэффициентов распространенности у женщин более стабильна, чем у мужчин, но в тоже время рост распространенности злокачественных новообразований наблюдается для всех без исключения рассматриваемых локализаций. Не считая группы «другие ЗНО», больше всего распространены ЗНО молочной железы и женских половых органов, для которых также наблюдается наибольшая скорость роста, за ними следуют колоректальный рак, ЗНО желудка и трахеи, бронхов и легкого. Локализация с наименьшей распространенностью - ЗНО губы, полости рта, глотки и пищевода.

Не считая несвойственных обоим полам локализаций, мы наблюдаем следующие структурные различия в распространенности злокачественных новообразований у мужчин и у женщин: если у мужчин ЗНО трахеи, бронхов и легкого более распространены, чем ЗНО губы, полости рта, глотки и пищевода, а ЗНО желудка являются наименее распространенной локализацией, то у женщин более распространены именно ЗНО желудка, 
за ними следуют ЗНО трахеи, бронхов и легкого, наименее распространёны ЗНО губы, полости рта, глотки и пищевода. В целом распространённость ЗНО в женском населении превосходит таковую в мужском, несмотря на то, что заболеваемость ЗНО в мужском населении гораздо выше, чем в женском. В последние годы наблюдения фиксируется тенденция к ускорению роста стандартизованного по возрасту показателя распространённости ЗНО в населении РФ, причем наиболее выраженного именно у мужчин. Примером могут служить локализации «ЗНО трахеи, бронхов и легкого» и «ЗНО предстательной железы».

Рассмотрим коэффициенты распространенности, сравнив показатели 2016 и 1999 г. За рассматриваемый период динамика стандартизованных по возрасту коэффициентов распространенности была следующей.

У мужчин:

- $\quad$ все $3 \mathrm{HO}$ - рост в 1,8 раза,

- другие $3 \mathrm{HO}$ - рост в 1,7 раза,

- ЗНО предстательной железы - рост в 5,2 раза,

- колоректальный рак - рост в 2,5 раза,

- ЗНО губы, полости рта, глотки и пищевода - снижение в 0,1 раза,

- 3 ЗНО трахеи, бронхов и легкого и 3 НО желудка - рост в 1,6 раза.

У женщин:

- $\quad$ все $3 Н О$ и другие $3 \mathrm{HO} \mathrm{-} \mathrm{рост} \mathrm{в} 1,6$ раза,

- $3 Н О$ женских половых органов - рост в 1,8 раза,

- ЗНО молочной железы - рост в 2,1 раза,

- колоректальный рак - рост в 2 раза,

- $3 \mathrm{HO} \mathrm{желудка} \mathrm{-} \mathrm{рост} \mathrm{в} \mathrm{1,2} \mathrm{раза,}$

- 3 ЗНО трахеи, бронхов и легкого - рост в 2,5 раза,

ЗНО губы, полости рта, глотки и пищевода - рост в 1,2 раза.

Исходя из полученных при помощи модели Дюшен данных, мы делаем вывод о росте распространенности $3 \mathrm{HO}$ всех локализаций в населении РФ, за исключением незначительного снижения коэффициентов распространенности ЗНО губы, полости рта, глотки и пищевода у мужчин.

\section{ОБСУЖДЕНИЕ}

Полученные результаты позволяют утверждать, что распространенность ЗНО в населении России увеличивается, а следовательно, растет и роль ЗНО как фактора инвалидизации населения. В последние годы наблюдения фиксируется тенденция к ускорению роста стандартизованного по возрасту показателя распространённости ЗНО в населении РФ, наиболее выраженная у мужчин. Примером могут служить ЗНО трахеи, бронхов и легкого(С33-С34), предстательной железы (С61), желудка (C16). В этот период не наблюдается значительного ускорения роста показателя средней продолжительности 
болезни, однако отмечается тенденция к росту стандартизованного по возрасту показателя заболеваемости населения РФ всеми ЗНО (рисунок 1), наиболее выраженная в мужском населении. Таким образом, можно предположить, что рост заболеваемости также играет важную роль в росте распространенности ЗНО в населении РФ, по крайней мере, в разрезе названных локализаций. Так, несмотря на то, что средняя продолжительность болезни у женщин больше, чем у мужчин распространенность, например, ЗНО трахеи, бронхов и лёгкого (C33-C34) и желудка (C16) у мужчин превосходит таковую у женщин.

Наибольший рост коэффициентов распространенности приходится на ЗНО предстательной железы (C61), однако наиболее вероятной причиной такого роста может служить гипердиагностика как результат практики проведения процедуры скрининга на рак простаты [Bray, Parkin 2009]. Единственной локализацией, для которой наблюдается незначительное снижение коэффициентов распространенности, являются ЗНО губы, полости рта, глотки и пищевода $(\mathrm{C} 00-\mathrm{C} 15)$ у мужчин. Несмотря на то, что заболеваемость в мужском населении значительно выше, чем в женском, распространенность ЗНО у последних выше, чем у мужчин, что может свидетельствовать в пользу гипотезы о лучшей выживаемости женщин, больных ЗНО, выраженной большей, по сравнению с мужчинами, продолжительностью болезни. Следует также отметить существующую в будущем угрозу роста женской смертности от злокачественных новообразований. Так как число умерших от рака является функцией роста заболеваемости, то наблюдаемый для женского населения рост последней может в дальнейшем выразиться в увеличении числа умерших от рака.

Средний возраст заболевания ЗНО и средний возраст смерти от них за рассматриваемый период росли, казалось бы, независимо. Мужчины за рассматриваемый период стали заболевать ЗНО позже, чем женщины, подтверждая гипотезу о смещении модального возраста заболевания ЗНО в старшие возрастные интервалы. В тоже время наблюдается рост среднего возраста смерти, более значительный, чем рост среднего возраста заболевания. Следовательно, модальные значения возраста смерти от ЗНО также смещаются в сторону старших возрастных интервалов. У женщин отмечается аналогичная мужчинам динамика. Рост среднего возраста заболевания уступает росту среднего возраста смерти. Единственной локализацией, для которой наблюдается обратная динамика, являются 3НО губы, полости рта, глотки и пищевода (C00-C15) у женщин, для которой наблюдается снижение как возраста смерти, так и возраста заболевания, причем снижение возраста смерти более значительно. Несмотря на то, что минимальный возраст заболевания ЗНО рассматриваемых локализаций приходится на разные годы, максимальное значение во всех рассматриваемых нами случаях приходилось либо на 2016, либо на один из нескольких предшествующих ему годов. Следствием динамики наблюдаемых процессов является и рост средней продолжительности болезни, фиксирующийся для всех рассматриваемых локализаций как у мужчин, так и у женщин, за исключением локализации «ЗНО губы, полости рта, глотки и пищевода» (C00-C15) у женщин.

В настоящее время в работах, посвященных проблеме заболеваемости хроническими болезнями и последующей смертности от них, весьма популярна концепция компрессии заболеваемости. Автор концепции [Fries 1980, 2002, 2005] выдвигает следующее предположение: в случае, если в населении наблюдается рост ожидаемой 
продолжительности жизни, одновременно с этим должна происходить и так называемая компрессия заболеваемости, выраженная в сокращении числа лет жизни, прожитых в состоянии неполного здоровья. Согласно выдвигаемой им гипотезе, снижение коэффициентов заболеваемости хроническими болезнями будет происходить по аналогии с наблюдавшимся ранее снижением смертности. Автор также предполагает, что будет наблюдаться смещение среднего возраста заболевания в сторону старших возрастов, иными словами будет сокращаться время между началом заболевания и смертью (это и есть компрессия заболеваемости) [Crimmins, Beltrán-Sánchez 2011]. Мы видим, что рост среднего возраста заболевания ЗНО действительно наблюдается в России. Однако одновременно с этим отмечается гораздо более значительный рост среднего возраста смерти от ЗНО. В результате этих процессов, подкрепленных снижением смертности от ЗНО и отсутствием снижения заболеваемости $3 \mathrm{HO}$, происходит рост распространенности ЗНО. Он определяется как ростом продолжительности болезни, являющимся в том числе и результатом лучшей выживаемости онкологических больных, так и ростом стандартизованных коэффициентов заболеваемости для диагностической категории «все ЗНО». Это позволяет сделать вывод, что в населении России в разрезе рассмотренных нами диагностических категорий ЗНО не наблюдается феномена компрессии заболеваемости. В противоположность этому наблюдается феномен экспансии заболеваемости, выраженный в увеличении среднего количества лет, прожитого населением в состоянии нездоровья, обусловленного ЗНО. Исключением является локализация «ЗНО губы, полости рта, глотки и пищевода» (C00-C15) у женщин, для которой наблюдается компрессия заболеваемости, выраженная в снижении числа лет, прожитых с ЗНО. В мужском населении компрессия заболеваемости для этой локализации не наблюдается, несмотря на некоторое снижение стандартизованного коэффициента распространённости, так как одновременно происходит рост среднего числа лет, прожитых с ЗНО.

Результатом наблюдаемой динамики могут стать дальнейший рост распространённости ЗНО и дальнейшее увеличение роли ЗНО как фактора инвалидизации населения.

В заключение скажем несколько слов об ограничениях данного исследования. При интерпретации полученных результатов следует помнить, что используемая нами модель Д. Дюшен не является мультистатусной в полной мере, но лишь приближенной или искусственной. Модель обладает двумя особенностями, результатом которых могут оказаться отрицательные значения функции дожития. С учетом доступности данных мы вынуждены рассчитывать показатель заболеваемости по отношению ко всему населению, a не только к здоровым людям, т.е. использовать не показатель интенсивности заболеваемости, но так называемый коэффициент второго порядка. Смертность в рамках модели также относится ко всему населению, а не только к больным ЗНО определенной диагностической категории. В результате мы получаем приближенные показатели. Тем не менее, так как все показатели рассчитаны с использованием идентичного метода, анализ их динамики и ее сравнение для мужского и женского населения имеют смысл.

Важно также отметить одну из фундаментальных особенностей модели Д. Дюшен. В рамках этой модели синтетическая когорта изначально делится на 2 группы: группу больных и группу здоровых. Предполагается, что выбытие из первой группы 
осуществляется не только в результате воздействия изучаемой причины, но также и других, отличных от нее причин. Сама модель основывается на применении двух частных моделей заболеваемость-смертность. Первая из них не учитывает возможность ремиссии и в свою очередь состоит из двух моделей двойного выбытия, в рамках которых члены синтетической когорты либо остаются в группе здоровых, либо выбывают из нее вследствие перехода в группу заболевших, либо в группу умерших от причин, отличных от рассматриваемой. Таким образом, заболевшие члены когорты могут, в свою очередь, выбыть из-под наблюдения вследствие смерти как от рассматриваемой причины, так и от иной отличной от нее причины.

Вторая модель принимает во внимание возможность ремиссии и включает в себя три взаимосвязанных состояния: отсутствие данного заболевания, его наличие , выбытие из-под наблюдения вследствие смерти. Между этими тремя состояниями осуществляется 4 перехода, которые можно охарактеризовать как заболевание, ремиссия, смерть от рассматриваемой причины или от любой иной причины. Таким образом, в рамках модели смертность гипотетического поколения вследствие причин, отличных от изучаемой, принимается за равную таковой в здоровом населении (т.е. в населении, не страдающим от данного заболевания). Безусловно, такое допущение является слабой стороной модели, так как очевидно, что структура смертности населения, больного ЗНО, отличается от таковой у здорового населения в силу воздействия иных факторов риска и поведенческих факторов. Следует также учесть, что так как в рамках модели существует возможность выбытия изпод наблюдения вследствие смерти от причины, отличной от рассматриваемой, часть смертей пациентов, рассматриваемых в модели по поводу одной локализации ЗНО, но умерших от другой, попадает в группу «другие 3НО».

Другой проблемой является неполная сопоставимость данных по смертности с данными по заболеваемости. За рассматриваемый период отчетная форма по заболеваемости и смертности менялась один раз в 2011 г. (до этого отчетная форма по смертности менялась в 1999 г.) [Петрова и др. 2015]. Таким образом, данные, опубликованные Институтом им. П.А. Герцена за рассматриваемый нами период, различаются полнотой перечня локализаций. К примеру, в публикуемых Институтом им. П.А. Герцена данных по заболеваемости вплоть до 2011 г. отсутствуют коды МКБ-10, соответствующие таким локализациям, как 3НО тонкого кишечника (C17) у мужчин и у женщин, а также ряд локализаций, относящихся к классу «ЗНО женских половых органов»: ЗНО вульвы (C51) и ЗНО влагалища (C52). Данный фактор следует обязательно учитывать при интерпретации результатов, полученных при помощи модели. Следует также помнить, что в России сбор данных по заболеваемости и по смертности по причинам смерти осуществляется независимо двумя различными ведомствами (Минздравом и Росстатом), что также может сказываться на полноте данных и их сопоставимости.

Совокупность этих двух факторов, т.е. неполной сопоставимости данных по смертности и заболеваемости, а также того, что модель не является в полной мере мультистатусной, и определяет возникающую при расчете модели проблему отрицательного дожития для диагностической группы «другие ЗНО» у мужчин. Следует также отметить, что средняя продолжительность болезни в связи с этими фактами является 
наименее надежным из всех полученных нами показателей, так как представляет собой разность показателей, рассчитанных на основании данных, полученных из независимых источников (форма С51 и форма №7).

\section{ЗАКЛЮЧЕНИЕ}

Следует отдельно отметить, что анализ роста распространенности ЗНО в населении сам по себе является малоинформативным, так как такой рост может являться как функцией роста заболеваемости, так и следствием лучшей выживаемости онкологических больных. Очевидно, что в случае если рост распространённости наблюдается в значительной степени вследствие увеличения заболеваемости, то ему следует дать в целом негативную оценку, однако если такой же рост происходит вследствие лучшей выживаемости пациентов уже больных 3НО, то это несомненно положительный тренд. К сожалению показатель распространенности 3 НО в населении не позволят дать однозначный ответ на поставленный таким образом вопрос, а следовательно необходимо анализировать его в совокупности с другими популяционными характеристиками рака.

В данной работе мы применили модель Д. Дюшен и таблицы множественного выбытия на ее основе для оценки ряда неизвестных характеристик онкологической смертности и заболеваемости населения РФ в разрезе рассматриваемых диагностических категорий. Мы оценили распространенность ЗНО, средний возраст заболевания и смерти от ЗНО и среднюю продолжительность болезни. На основании полученных результатов можно предположить, что, несмотря на то что рост распространённости ЗНО в населении РФ является, в том числе, и результатом роста заболеваемости, он также обусловлен и ростом средней ожидаемой продолжительности болезни, косвенно подтверждая гипотезу, о лучшей выживаемости онкологических больных. Наблюдаемое смещение среднего возраста заболеваемости и среднего возраста смерти от ЗНО рассматриваемых локализаций в старшие возрастные интервалы, выражается в увеличении средней продолжительности болезни рассматриваемой как разность среднего возраста смерти и среднего возраста заболевания ЗНО. Данная тенденция предопределяет феномен экспансии заболеваемости, наблюдаемый для всех рассмотренных групп ЗНО, за исключением группы «ЗНО губы, полости рта и пищевода» (C00-C15) у женщин, для которой наблюдается сокращение средней продолжительности болезни или компрессия заболеваемости. В настоящее время в РФ в целом подтверждается не только смещение заболевания ЗНО в старший возраст, но также есть и косвенные свидетельства улучшения прогноза на выживаемость, что и выражается в росте распространенности ЗНО. Таким образом, основываясь на наблюдаемой динамике популяционных процессов, можно выдвинуть гипотезу о вероятности дальнейшего увеличения роли ЗНО как фактора инвалидизации населения РФ.

\section{ЛИТЕРАТУРА}

Андреев Е.М., Е.А. Кваша, Т.Л. Харькова (2014). Продолжительность жизни в России: восстановительный рост // Демоскоп Weekly. 621-622. URL: 
http://www.demoscope.ru/weekly/2014/0621/demoscope621.pdf (дата обращения: 01.04.2018).

Вишневский А.Г. (2014). Смертность в России: несостоявшаяся вторая эпидемиологическая революция // Демографическое обозрение. 1(4). URL: https://demreview.hse.ru/article/view/1801/2524 (дата обращения: 20.03.2018).

Каприн А.Д., В.В. Старинский, Г.В. Петрова (2014). Злокачественные новообразования в России в 2012 году (заболеваемость и смертность) // ФГБУ МНИОИ им. П.А. Герцена. M.: Министерство здравоохранения и социального развития России. URL: http://www.oncology.ru/service/statistics/malignant_tumors/2012.pdf (дата обращения: 07.03.2018).

Каприн А.Д., В.В. Старинский, Г.В. Петрова (2015). Злокачественные новообразования в России в 2013 году (заболеваемость и смертность) // ФГБУ МНИОИ им. П.А. Герцена. М.: Министерство здравоохраненияРоссии. URL: http://www.oncology.ru/service/statistics/malignant_tumors/2013.pdf (дата обращения: 07.03.2018).

Каприн А.Д., В.В. Старинский, Г.В. Петрова (2016). Злокачественные новообразования в России в 2014 году (заболеваемость и смертность) // ФГБУ МНИОИ им. П.А. Герцена. М.: Министерство здравоохранения России. URL:

http://www.oncology.ru/service/statistics/malignant_tumors/2014.pdf (дата обращения: 07.03.2018).

Каприн А.Д., В.В. Старинский, Г.В. Петрова (2017). Злокачественные новообразования в России в 2015 году (заболеваемость и смертность) // ФГБУ МНИОИ им. П.А. Герцена. M.: Министерство здравоохранения России. URL:

http://www.oncology.ru/service/statistics/malignant_tumors/2015.pdf (дата обращения: 07.03.2018).

Каприн А.Д., В.В. Старинский, Г.В. Петрова (2018а). Злокачественные новообразования в России в 2016 году (заболеваемость и смертность) // ФГБУ МНИОИ им. П.А. Герцена. М.: Министерство здравоохранения России. URL:

http://www.oncology.ru/service/statistics/malignant_tumors/2016.pdf (дата обращения: 07.03.2018).

Каприн А.Д., В.В. Старинский, Г.В. Петрова (2018b). Состояние онкологической помощи населению России в 2017 году // ФГБУ МНИОИ им. П.А. Герцена. М.: Министерство здравоохраненияРоссии. URL:

http://www.oncology.ru/service/statistics/condition/2017.pdf (дата обращения: 10.05.2018).

Петрова Г.В., А.Д. Каприн, О.П. Грецова, В.В. Старинский (2015). Злокачественные новообразования в России обзор статистической информации за 1993-2013 гг. // ФГБУ МНИОИ им. ПА Герцена. М.: Министерство здравоохранения России. URL: http://www.oncology.ru/service/statistics/malignant_tumors/1993-2013.pdf (дата обращения: 07.03.2018).

Петрова Г.В., В.В. Старинский, О.П. Грецова (2016). Оценка качества учета умерших больных со злокачественным новообразованиями в России // Исследования и практика в медицине. 3(4): 70-74.

Чиссов В.И., В.В. Старинский, Г.В. Петрова (2010). Злокачественные новообразования в России в 2008 году (заболеваемость и смертность) // ФГБУ МНИОИ им. П.А. Герцена. М.: Министерство здравоохранения и социального развития России. URL: 
http://www.oncology.ru/service/statistics/malignant_tumors/2008.pdf (дата обращения: 07.03.2018).

Чиссов В.И., В.В. Старинский, Г.В. Петрова (2009). Злокачественные новообразования в России в 2007 году (заболеваемость и смертность) // ФГБУ МНИОИ им. П.А. Герцена. М.: Министерство здравоохранения и социального развития России. URL:

http://www.oncology.ru/service/statistics/malignant_tumors/2007.pdf (дата обращения: 07.03.2018).

Чиссов В.И., В.В. Старинский, Г.В. Петрова (2011). Злокачественные новообразования в России в 2009 году (заболеваемость и смертность) // ФГБУ МНИОИ им. П.А. Герцена. M.: Министерство здравоохранения и социального развития России. URL: http://www.oncology.ru/service/statistics/malignant_tumors/2009.pdf (дата обращения: 07.03.2018).

Чиссов В.И., В.В. Старинский, Г.В. Петрова (2012). Злокачественные новообразования в России в 2010 году (заболеваемость и смертность) // ФГБУ МНИОИ им. П.А. Герцена. М.: Минздравсоцразвития России. URL: http://www.oncology.ru/service/statistics/malignant_tumors/2010.pdf (дата обращения: 07.03.2018).

Чиссов В.И., В.В. Старинский, Г.В. Петрова (2013). Злокачественные новообразования в России в 2011 году (заболеваемость и смертность) // ФГБУ МНИОИ им. П.А. Герцена. М.: Министерство здравоохранения и социального развития России. URL: http://www.oncology.ru/service/statistics/malignant_tumors/2011.pdf (дата обращения: 07.03.2018).

Щербакова Е.М. (2018). Россия: предварительные демографические итоги 2017 года часть II // Демоскоп Weekly. 761-762. URL: http://demoscope.ru/weekly/2017/0761/barom01.php (дата обращения: 05.04.2018).

Andreev E.M., V.M. Shkolnikov, D. Jasilionis (2018). Two demographic models for estimation of population-level burden of cancer: an excel spreadsheet // MPIDR - 2018. URL: https://www.demogr.mpg.de/papers/technicalreports/tr-2018-004.pdf (дата обращения: 10.05.2018).

Bray F., A. Jemal, N. Grey, J. Ferlay, D. Forman (2012). Global cancer transitions according to the human development index (2008-2030): a population-based study // The Lancet oncology. 13(8): 790-801.

Bray F., D. Parkin (2009). Evaluation of data quality in the cancer registry: principles and methods part I: Comparability, validity and timeliness // European journal of cancer. 45(5): $747-755$.

Crimmins E., H. Beltrán-Sánchez (2011). Mortality and morbidity trends: is there a compression of morbidity? // The journals of gerontology series B: psychological sciences and social sciences. $66 \mathrm{~B}(1)$ : $75-86$.

Duchêne J. (2002). The Measurement of mortality by cause and of morbidity: the life table // Springer. 209-244.

Fries J. (2002). Aging, natural death, and the compression of morbidity // Bulletin of the World Health Organization. 80: 245-250.

Fries J. (1980). Aging, natural death, and the compression of morbidity // The new England journal of medicine. 303(3): 130-135.

Fries J. (2005). The compression of morbidity // The Milbank quarterly. 83(4): 801-823. 
Grigoriev P., F. Meslé, V.M. Shkolnikov, E.M. Andreev, A. Fihel, M. Pechholdova, J. Vallin (2014). The recent mortality decline in Russia: beginning of the cardiovascular revolution? // Population and development review. 40(1): 107-129.

Shkolnikov V.M., E.M. Andreev, M. McKee, D. Leon (2013). Components and possible determinants of decrease in Russian mortality in 2004-2010 // Demographic Research. 28(32): 917-50. URL: https://www.demographic-research.org/volumes/vol28/32/28-32.pdf (дата обращения: 09.04.2018).

World Health Organization factsheet (2017). URL: http://www.who.int/en/news-room/factsheets/detail/cancer (дата обращения: 30.03.2018). 


\title{
AN EVALUATION OF THE PREVALENCE OF MALIGNANT NEOPLASMS IN RUSSIA USING AN INCIDENCE-MORTALITY MODEL
}

\section{RUSTAM TURSUN-ZADE}

\begin{abstract}
This paper aims to estimate the cancer mortality and morbidity derivatives for the Russian population given the limited access to medical and demographic data. The multiple-decrement life table method-also known as the population model of cancer - was originally proposed by J. Duchene and makes it possible to assess otherwise inaccessible indicators, such as the prevalence of cancer in the Russian population. Applying this model to the publicly available data on cancer mortality and morbidity, we were able to estimate the following indicators for the Russian population: average age at malignant neoplasms (MN) diagnosis, average duration of disease, prevalence of $M N$, and average age at death from $M N$. We aimed to determine whether the prevalence of MN is increasing in the Russian Federation and whether this growth is occurring due to expansion of morbidity.

It was found that the average age at cancer diagnosis, along with the average age at death from cancer, is increasing in the Russian population, with the primacy of the latter. These processes are in turn resulting in an increase of the average number of years lived with cancer, hence justifying the claim for an expansion of morbidity. This phenomenon, along with the increase in the incidence of $M N$, is the cause of the increase in MN prevalence in Russia.

Localizations with the highest and lowest MN prevalence were identified, as well as localizations for which the expansion of morbidity phenomenon does not occur. It was found that in Russia the general trend is for the expansion of morbidity, expressed in an increase of the number of years lived in an imperfect health condition. MN of the lip, oral cavity and esophagus (COO-C15) in women is the only localization for which this phenomenon is not observed. This localization is the only exception to the otherwise observed expansion of morbidity. The main limitations and drawbacks of the study are discussed in a separate section.
\end{abstract}

Key words: multiple decrement life-tables, incidence and mortality of malignant neoplasms, prevalence of malignant neoplasms, derivatives of cancer mortality and incidence, oncological statistics, cancer data analysis.

\footnotetext{
Rustam Tursun-ZADE (rtursun-zade@hse.ru), NATIONAL RESEARCH University Higher SchOOL OF ECONOMICS, RUSSIA.

THIS STUDY WAS FUNDED BY THE STATE SUPPORT PROGRAM FOR LEADING UNIVERSITIES OF THE RUSSIAN FEDERATION: «5-100».

DATE RECEIVED: JULY 2018.
}

\section{REFERENCES}

Andreev E.M., E.A. Kvasha, T.L. Kharkova (2014). Prodolzhitel'nost' zhizni v Rossii: vosstanovitel'nyy rost [Life expactanccy in Russia: the compensatory increase] // Demoskop Weekly [Demoscope Weekly]. 621-622. URL: http://www.demoscope.ru/weekly/2014/0621/demoscope621.pdf (accessed: 01.04.2018).

Andreev E.M., V.M. Shkolnikov, D. Jasilionis (2018). Two demographic models for estimation of population-level burden of cancer: an excel spreadsheet // MPIDR - 2018. URL: https://www.demogr.mpg.de/papers/technicalreports/tr-2018-004.pdf (accessed: 10.05.2018). 
Bray F., A. Jemal, N. Grey, J. Ferlay, D. Forman (2012). Global cancer transitions according to the human development index (2008-2030): a population-based study // The Lancet oncology. 13(8): 790-801.

Bray F., D. Parkin (2009). Evaluation of data quality in the cancer registry: principles and methods part I: Comparability, validity and timeliness // European journal of cancer. 45(5): $747-755$.

Chissov V.I., V.V. Starinskiy, G.V. Petrova (2009). Zlokachestvennye novoobrazovaniya v Rossii v 2007 godu (zabolevaemost' i smertnost') [Malignant neoplasms in Russia in 2009 (mortality and incidence)] // FGBU MNIOI im. P.A. Gertsena [FGBA MROI named after P.A Gertsen]. Moscow: Ministerstvo zdravookhraneniya i sotsial'nogo razvitiya Rossii. URL: http://www.oncology.ru/service/statistics/malignant_tumors/2007.pdf (accessed: 07.03.2018).

Chissov V.I., V.V. Starinskiy, G.V. Petrova (2010). Zlokachestvennye novoobrazovaniya v Rossii v 2008 godu (zabolevaemost' i smertnost') [Malignant neoplasms in Russia in 2008 (mortality and incidence)] // FGBU MNIOI im. P.A. Gertsena [FGBA MROI named after P.A Gertsen]. Moscow: Ministerstvo zdravookhraneniya i sotsial'nogo razvitiya Rossii. URL: http://www.oncology.ru/service/statistics/malignant_tumors/2008.pdf (accessed: 07.03.2018).

Chissov V.I., V.V. Starinskiy, G.V. Petrova (2011). Zlokachestvennye novoobrazovaniya v Rossii v 2009 godu (zabolevaemost' i smertnost') [Malignant neoplasms in Russia in 2009 (mortality and incidence)] // FGBU MNIOI im. P.A. Gertsena [FGBA MROI named after P.A Gertsen]. Moscow: Ministerstvo zdravookhraneniya i sotsial'nogo razvitiya Rossii. URL: http://www.oncology.ru/service/statistics/malignant_tumors/2009.pdf (accessed: 07.03.2018).

Chissov V.I., V.V. Starinskiy, G.V. Petrova (2012). Zlokachestvennye novoobrazovaniya v Rossii v 2010 godu (zabolevaemost' i smertnost') [Malignant neoplasms in Russia in 2010 (mortality and incidence)]// FGBU MNIOI im. P.A. Gertsena [FGBA MROI named after P.A Gertsen]. Moscow: Minzdravsotsrazvitiya Rossii. URL:

http://www.oncology.ru/service/statistics/malignant_tumors/2010.pdf (accessed: 07.03.2018).

Chissov V.I., V.V. Starinskiy, G.V. Petrova (2013). Zlokachestvennye novoobrazovaniya v Rossii v 2011 godu (zabolevaemost' i smertnost') [Malignant neoplasms in Russia in 2011 (mortality and incidence)] // FGBU MNIOI im. P.A. Gertsena [FGBA MROI named after P.A Gertsen]. Moscow: Ministerstvo zdravookhraneniya i sotsial'nogo razvitiya Rossii. URL: http://www.oncology.ru/service/statistics/malignant_tumors/2011.pdf (accessed: 07.03.2018).

Crimmins E., H. Beltrán-Sánchez (2011). Mortality and morbidity trends: is there a compression of morbidity? // The journals of gerontology series B: psychological sciences and social sciences. 66B(1): 75-86.

Duchêne J. (2002). The Measurement of mortality by cause and of morbidity: the life table // Springer. 209-244.

Fries J. (1980). Aging, natural death, and the compression of morbidity // The new England journal of medicine. 303(3): 130-135.

Fries J. (2002). Aging, natural death, and the compression of morbidity // Bulletin of the World Health Organization. 80: 245-250.

Fries J. (2005). The compression of morbidity // The Milbank quarterly. 83(4): 801-823. 
Grigoriev P., F. Meslé, V.M. Shkolnikov, E.M. Andreev, A. Fihel, M. Pechholdova, J. Vallin (2014). The recent mortality decline in Russia: beginning of the cardiovascular revolution? // Population and development review. 40(1): 107-129.

Kaprin A.D., V.V. Starinskiy, G.V. Petrova (2014). Zlokachestvennye novoobrazovaniya V Rossii v 2012 godu (zabolevaemost' i smertnost') [Malignant neoplasms in Russia in 2012 (mortality and incidence)] // FGBU MNIOI im. P.A. Gertsena [FGBA MROI named after P.A Gertsen]. Moscow: Ministerstvo zdravookhraneniya Rossii. URL:

http://www.oncology.ru/service/statistics/malignant_tumors/2012.pdf (accessed: 07.03.2018).

Kaprin A.D., V.V. Starinskiy, G.V. Petrova (2015). Zlokachestvennye novoobrazovaniya v Rossii v 2013 godu (zabolevaemost' i smertnost') [Malignant neoplasms in Russia in 2013 (mortality and incidence)] // FGBU MNIOI im. P.A. Gertsena [FGBA MROI named after P.A Gertsen]. Moscow: Ministerstvo zdravookhraneniya Rossii. URL: http://www.oncology.ru/service/statistics/malignant_tumors/2013.pdf (accessed: 07.03.2018).

Kaprin A.D., V.V. Starinskiy, G.V. Petrova (2016). Zlokachestvennye novoobrazovaniya V Rossii v 2014 godu (zabolevaemost' i smertnost') [Malignant neoplasms in Russia in 2014 (mortality and incidence)] // FGBU MNIOI im. P.A. Gertsena [FGBA MROI named after P.A Gertsen]. Moscow: Ministerstvo zdravookhraneniya Rossii. URL:

http://www.oncology.ru/service/statistics/malignant_tumors/2014.pdf (accessed: 07.03.2018).

Kaprin A.D., V.V. Starinskiy, G.V. Petrova (2017). Zlokachestvennye novoobrazovaniya v Rossii v 2015 godu (zabolevaemost' i smertnost') [Malignant neoplasms in Russia in 2015 (mortality and incidence)]// FGBU MNIOI im. P.A. Gertsena [FGBA MROI named after P.A Gertsen]. Moscow: Ministerstvo zdravookhraneniya Rossii. URL: http://www.oncology.ru/service/statistics/malignant_tumors/2015.pdf (accessed: 07.03.2018).

Kaprin A.D., V.V. Starinskiy, G.V. Petrova (2018a). Zlokachestvennye novoobrazovaniya v Rossii v 2016 godu (zabolevaemost' i smertnost') [Malignant neoplasms in Russia in 2016 (mortality and incidence)] // FGBU MNIOI im. P.A. Gertsena [FGBA MROI named after P.A Gertsen]. Moscow: Ministerstvo zdravookhraneniya Rossii. URL: http://www.oncology.ru/service/statistics/malignant_tumors/2016.pdf (accessed: 07.03.2018).

Kaprin A.D., V.V. Starinskiy, G.V. Petrova (2018b). Sostoyanie onkologicheskoy pomoshchi naseleniyu Rossii v 2017 godu [State of the oncological aid to Russian population in 2017] // FGBU MNIOI im. P.A. Gertsena [FGBA MROI named after P.A Gertsen]. Moscow: Ministerstvo zdravookhraneniya Rossii. URL: http://www.oncology.ru/service/statistics/condition/2017.pdf (accessed: 10.05.2018).

Petrova G.V., A.D. Kaprin, O.P. Gretsova, V.V. Starinskiy (2015). Zlokachestvennye novoobrazovaniya v Rossii obzor statisticheskoy informatsii za 1993-2013 gg. [Malignant neoplasms in Russia statistical review for 1993-2013] // FGBU MNIOI im. P.A. Gertsena [FGBA MROI named after P.A Gertsen]. Moscow: Ministerstvo zdravookhraneniya Rossii.URL: http://www.oncology.ru/service/statistics/malignant_tumors/1993-2013.pdf (accessed: 07.03.2018).

Petrova G.V., V.V. Starinskiy, O.P. Gretsova (2016). Otsenka kachestva ucheta umershikh bol'nykh so zlokachestvennym novoobrazovaniyami v Rossii [Assessments of the quality of 
accounting for deaths caused by malignant neoplasms in Russia] // Issledovaniya i praktika $\mathrm{V}$ meditsine [Research and practical medicine journal]. 3(4): 70-74.

Rosstat (2017). Demograficheskij ezhegodnik Rossii. Statisticheskij sbornik [The demographic yearbook of Russia] // M.: Rosstat. URL: http://www.gks.ru/free_doc/doc_2017/demo17.pdf (accessed 10.06.2018)

Shcherbakova E.M. (2018). Rossiya: predvaritel'nye demograficheskie itogi 2017 goda [Preliminary demographic resume for 2017]. Chast' II [part II] // Demoskop Weekly [Demoscope Weekly]. 761-762. URL: http://demoscope.ru/weekly/2017/0761/barom01.php (accessed: 05.04.2018).

Shkolnikov V.M., E.M. Andreev, M. McKee, D. Leon (2013). Components and possible determinants of decrease in Russian mortality in 2004-2010 // Demographic Research. 28(32): 917-50. URL: https://www.demographic-research.org/volumes/vol28/32/28-32.pdf (accessed: 09.04.2018).

Vishnevsky A.G. (2014). Smertnost' v Rossii: nesostoyavshayasya vtoraya epidemiologicheskaya revolyutsiya [Mortality in Russia: unfulfilled second epidemiologic revolution] // Demograficheskoe obozrenie [Demographic review]. 1(4). URL: https://demreview.hse.ru/article/view/1801/2524 (accessed: 20.03.2018).

World Health Organization factsheet (2017). URL: http://www.who.int/en/news-room/factsheets/detail/cancer (accessed: 30.03.2018). 